\title{
OS PLANOS ESTADUAIS DE EDUCAÇÃO E A GESTÃO DEMOCRÁTICA: UMA ANÁLISE DAS ESTRATÉGIAS ESTADUAIS
}

\author{
Márcio Alexandre Barbosa Lima ${ }^{\mathrm{I}}$
}

http://dx.doi.org/10.24109/9786581041076.ceppe.v2a7

\section{RESUMO}

Este estudo objetiva identificar as apropriações dos debates travados durante a Conferência Nacional de Educação (Conae) 2010 nos planos estaduais de educação. Para tanto, analisa as metas e estratégias desses planos relacionadas à gestão democrática, identificando suas relações com as resoluções da Conae 2010 e com o Plano Nacional de Educação (PNE), Lei no 13.005, de 25 de junho de 2014. Entre as conclusões, destaca-se que um dos principais temas abordados na Conae 2010, a avaliação institucional, foi retomado nos planos estaduais, notadamente como estratégia da gestão democrática, o que realça a importância das conferências e da participação social na efetivação das propostas aprovadas.

Palavras-chave: PNE; gestão democrática; participação; planos estaduais de educação. I Doutor em sociologia e pesquisador do Instituto Nacional de Estudos e Pesquisas Educacionais Anísio
Teixeira (Inep). E-mail: marcio.lima@inep.gov.br. 


\section{INTRODUÇÃO}

Ao longo dos últimos anos, ocorreram três conferências nacionais de educação: a Conferência Nacional de Educação (Conae) 2010, a Conae 2014 e a Conae 2018. A primeira delas forneceu elementos para que estados, municípios e a União elaborassem seus respectivos planos de educação. O presente trabalho analisou como os debates e os temas oriundos da Conae 2010 em torno da gestão democrática repercutiram nos planos estaduais e nacional de educação.

A participação da sociedade nessas conferências, analisando, aprovando propostas e contribuindo para o debate educacional, pode ser avaliada, ainda que indiretamente, na medida em que as deliberações das conferências foram retomadas nos planos estaduais em alguns temas relacionados à gestão democrática. O estudo também destacou a importância da participação na elaboração de políticas públicas educacionais e como essa participação em espaços deliberativos pode aperfeiçoar as políticas implementadas pelo poder público.

Além dessa introdução sobre planos estatais e participação social, na segunda parte do texto são analisadas as metas relacionadas à gestão democrática nos planos estaduais e nacional e, em seguida, são apresentados os resultados encontrados, com destaque para a avaliação - tema relacionado à gestão democrática mais frequente nos planos estaduais.

\section{OS PLANOS ESTATAIS E A PARTICIPAÇÃO SOCIAL}

Na educação, a primeira vez que surgiu a ideia de um plano nacional foi no Manifesto dos Pioneiros da Educação, em 1932. O documento sugeriu uma série de propostas para a implantação de políticas públicas que se inserem em um quadro de racionalidade e sistematização (Souza, 2014). O Manifesto, amparado no pressuposto de que a ausência de integração entre os planos econômicos e educacionais constituía um dos limites que a República vivenciava em seus intentos reformistas até então, diagnosticava que "todos os nossos esforços, sem unidade de plano e sem espírito de continuidade, não lograram ainda criar um sistema de organização escolar, à altura das necessidades modernas e das necessidades do país” (Manifesto..., 2010, p. 33).

Mais tarde, em 1961, a Lei de Diretrizes e Bases (LDB) buscou levar a cabo reformas no campo educacional que respondessem aos anseios de modernização e desenvolvimento em voga. Em período mais recente, 1993, foi criado o Plano Decenal de Educação para Todos, elaborado pelo Ministério da Educação (MEC) e destinado a cumprir as resoluções da Conferência Mundial de Educação para Todos, entre 1993 e 2003. Em 2001, o Congresso Nacional aprovou o Plano Nacional de Educação (PNE) 2001-2010 (Brasil, 2001) e está em vigência o PNE 2014-2024. 
A criação de planos nacionais de educação decorre de diversas determinações legais. O art. 214 da Constituição Federal do Brasil (CF), modificado pela Emenda Constitucional $n^{0}$ 59/2009, estabelece a aprovação de um Plano Nacional de Educação de duração decenal; a LDB, Lei $\mathrm{n}^{\circ}$ 9.394/1996, no art. $9^{\circ}$, determina que a União e os estados devem elaborar seus respectivos planos de educação, enquanto a Lei do PNE estende essa obrigação aos municípios. O PNE, Lei $n^{0} 13.005 / 2014$, reafirma essa determinação, em seu art. $8^{\circ}$, acrescentando que ocorrerá "em consonância com as diretrizes, metas e estratégias previstas no PNE", e "com ampla participação de representantes da comunidade educacional e da sociedade civil” (Brasil, 2014).

O PNE (2001-2010) estabelecia a necessidade de estados e municípios elaborarem seus respectivos planos de educação, mas, ao final de sua vigência, apenas 14 estados haviam aprovado planos estaduais e 2.181 municípios (39,28\%), seus planos municipais de educação (Souza, 2014). Cumpre registrar que, apesar da existência de planos anteriores, esse foi o primeiro plano nacional de educação aprovado pelo Congresso Nacional.

Muitos afirmaram que a dificuldade para o cumprimento das metas do PNE 2001-2010 foi a ausência de obrigação legal fixando, na lei do Plano, os percentuais do orçamento da União destinados exclusivamente à educação. Para outros, os vetos presidenciais foram fundamentais para que o Plano acabasse se tornando uma carta de intenções (Souza, 2014), destino previsto por outros autores, como Cury (2009), Sguissardi (2006) e Monlevade (2001).

Para o novo Plano Nacional de Educação 2014-2024 reduziram-se as metas e estabeleceram-se centenas de estratégias para o seu alcance, dentre elas a determinação de ampliar os investimentos na educação de modo a atingir 7\% do Produto Interno Bruto (PIB) no quinto ano de vigência do Plano Nacional e o equivalente a $10 \%$ do PIB até o final do decênio (Brasil, 2014), com a expectativa de garantir os recursos necessários que faltaram ao plano anterior.

Diversos fatores associados influenciaram os resultados alcançados nas metas dos planos nacionais de educação, sendo a falta de recursos uma das evidências mais robustas, mas não a única. A participação da sociedade na elaboração, no planejamento e na execução do PNE também pode ser considerada um fator determinante para o alcance de suas metas.

Nesse sentido, buscando responder por que muitos planos bem-intencionados elaborados por governos para melhorar as condições de vida da população falham, James Scott (1998) afirma existir quatro elementos que, combinados, são capazes de gerar resultados trágicos para essas populações. Suas reflexões permitem a elaboração de um quadro conceitual e analítico útil para a reflexão a respeito das razões do sucesso ou do fracasso de planos, sejam eles econômicos ou sociais.

O primeiro elemento considerado por Scott é o que ele chama de organização administrativa da natureza, ou seja, a capacidade do Estado de simplificar e padronizar a realidade com vistas a gerenciar melhor grandes agregados (Scott, 1998). 
São diversos meios e instrumentos que colocam a legibilidade da realidade como um problema central, criando padrões para o seu monitoramento, como censos, exames, avaliações, padronização de pesos e medidas, estabelecimento de sobrenomes e padronização da língua. Trata-se de um processo de padronização da realidade que, a princípio, reduz sua diversidade, mas permite um melhor controle, uma racionalização capaz de melhorar e aumentar a capacidade de intervenção do Estado. Com um olhar restrito aos dados observados, a complexidade é reduzida e isso permite ao Estado atuar de maneira mais eficiente sobre seu objeto de intervenção (Scott, 1998).

A capacidade de dar legibilidade à complexidade social por meio de padronização e simplificação, por si, não leva planos governamentais a falharem. $\mathrm{O}$ segundo elemento indicado por Scott para se chegar a isso é a ideologia modernista, apresentada pelo autor como uma forte confiança no progresso técnico-científico, no domínio da natureza e na capacidade de satisfação das necessidades por meio do crescimento. A ideologia modernista, portanto, é uma crença que empresta a legitimidade da ciência e da tecnologia. Seus propagadores pretendem usar o poder do Estado para produzir mudança nos hábitos, nos padrões de vida, na conduta moral e na visão de mundo da sociedade (Scott, 1998).

Quando esses dois elementos descritos acima encontram um Estado autoritário e forte, que consiste no terceiro elemento considerado pelo autor, essa combinação torna-se perigosa. Um Estado autoritário, segundo Scott (1998), pode usar de sua força para promover as mudanças propostas pela ideologia modernista com os instrumentos de legibilidade disponíveis. Esse processo gera consequências para as pessoas e para a sociedade, que reage ou não a essas intervenções. Assim, o quarto elemento é a existência de uma sociedade civil fraca, com pouca capacidade de resistência ao poder estatal. Esse quarto elemento conjugado com os outros três anteriores compõe o quadro necessário para o fracasso dos planos que supostamente foram criados para melhorar a vida das pessoas.

Nesse sentido, a participação da sociedade e os outros elementos apontados por Scott (1998) sugerem que uma das principais qualidades do atual PNE e sua principal diferença em relação aos anteriores é a forma participativa pela qual se deu sua elaboração.

Em 2008, durante a Conferência Nacional da Educação Básica, o governo federal comprometeu-se a organizar uma Conferência Nacional de Educação. Realizada em 2010, a Conae foi precedida por conferências municipais, realizadas no primeiro semestre de 2009, e estaduais, realizadas no segundo semestre do mesmo ano. O tema da Conferência era "Construindo o sistema nacional articulado: o Plano Nacional de Educação, diretrizes e estratégias de ação”. Um texto base foi utilizado pelos participantes das conferências municipais e estaduais de maneira que pudessem acrescentar ou suprimir propostas ao texto. 
Nessas conferências, sociedade civil, agentes públicos, entidades de classe, estudantes, profissionais da educação, pais e responsáveis se reuniram para debater a educação brasileira, constituindo um espaço social de discussão da educação. Segundo os organizadores, a Conae mobilizou cerca de 3,5 milhões de pessoas e contou com a participação de 450 mil delegados e delegadas nas etapas municipal, intermunicipal, estadual e nacional, envolvendo em torno de $2 \%$ da população do País (Brasil. MEC, 2010).

As propostas elaboradas nas conferências municipais foram debatidas e remetidas a cada conferência estadual de educação e, em seguida, encaminhadas à comissão organizadora da Conferência Nacional. Com base no debate sobre essas propostas, foi elaborado o documento final da Conae 2010, aprovado pelos delegados eleitos em cada uma das conferências municipais e estaduais. Segundo a comissão organizadora da Conferência, foram sugeridas mais de 5.000 deliberações que, após sistematização e debate, resultaram em 677 emendas aprovadas ao documento final.

O desenho de participação democrática, próprio da Conferência Nacional, apresentou características que Avritzer (2008) classificou como formas de participar de baixo para cima. A partir dos municípios foram eleitos delegados para as conferências estaduais e nacional, incorporando cidadãos e associações da sociedade civil no processo de construção do Plano e na deliberação sobre as políticas a serem implantadas.

Os resultados das discussões e aprovações na Conae foram apresentados ao Poder Executivo e, posteriormente, encaminhados ao Congresso Nacional por meio do Projeto de Lei (PL) $n^{\circ}$ 8.035/2010, que se transformou na Lei $n^{\circ} 13.005 / 2014$, a Lei do PNE.

A magnitude das mudanças na área da educação naquele momento era de tal ordem que, em novembro de 2009, um ano antes, o Congresso Nacional aprovou a Emenda Constitucional $\mathrm{n}^{\circ} 59$, estabelecendo que os planos nacionais de educação passariam a ter uma duração de dez anos, substituindo o texto original que determinava apenas que eles deveriam ser plurianuais, além de ampliar a obrigatoriedade do ensino para todas as etapas da educação básica.

As dificuldades para construção de consensos em torno do PL fizeram com que o projeto tramitasse no Congresso Nacional entre 2010 e 2014. Nesse processo legislativo, mais de 2.900 emendas parlamentares foram incluídas no projeto enviado pelo Poder Executivo (Peroni; Flores, 2014).

O novo Plano Nacional de Educação, portanto, é o resultado de um amplo e democrático debate nacional sobre educação, aprovado pelo Congresso Nacional e construído de maneira participativa, estabelecendo metas objetivas e estratégias para o seu alcance, com a participação de diversos setores da sociedade.

A Lei do PNE ainda tornou obrigatória a realização de pelo menos duas conferências nacionais de educação até o final do decênio, precedidas de conferências 
municipais, estaduais e distrital. Como já salientado, em 2014 ocorreu a II Conae e em 2018 a III Conae, com conferências preliminares de estados e municípios.

A realização das conferências representou uma etapa importante na elaboração do atual Plano Nacional e esse processo participativo pode ser determinante para o cumprimento dessas metas. Sem a participação da sociedade no monitoramento do Plano, corre-se o risco dele ser esquecido pelos poderes instituídos.

Uma crítica frequente ao Plano Nacional de Educação 2001-2010 era o fato de que estados e municípios não elaboraram seus respectivos planos de educação e a sociedade "ficou sem ferramentas para pressionar em nível local pela destinação de recursos para a realização das metas" (Peroni, Flores, 2014).

Esse problema foi corrigido na lei do atual PNE, ao determinar que todos os entes federativos deveriam elaborar seus correspondentes planos de educação, em consonância com as diretrizes, metas e estratégias previstas no PNE, no prazo de um ano.

Entretanto, quando se compara o documento final da Conae com o Projeto de Lei $\mathrm{n}^{\circ}$ 8.035/2010, encaminhado ao Congresso Nacional, fica evidente que a proposta, no que se refere à gestão democrática, não contemplou todas as propostas registradas no documento final da Conae 2010 (Gomes, 2015), observação que também pode ser estendida à Lei $\mathrm{n}^{0}$ 13.005/2014.

Considerando o processo de elaboração e aprovação do PNE, o trabalho analisa como o debate acumulado sobre a gestão democrática do ensino, durante o processo de realização das conferências municipais, estaduais e nacional, e materializado no documento final da Conferência, está presente no âmbito dos planos estaduais de educação.

Identificar quais temas compõem a gestão democrática nos planos estaduais e compará-los com os planos e temas debatidos e aprovados, permite analisar em que medida as deliberações da Conae foram retomadas nos estados e quais temas foram priorizados nos diversos planos estaduais.

Nesse sentido, a participação da sociedade nas propostas da Conferência Nacional de Educação pode ser aferida indiretamente na medida em que, ao analisarmos a forma como os planos estaduais contemplaram ou não as propostas do documento final da Conae, teremos condições de avaliar a influência efetiva dessas conferências em cada estado, materializada nas estratégias aprovadas nos planos estaduais.

A seguir serão analisados os documentos que fizeram parte desse processo legislativo e participativo, começando com as discussões contidas no documento final aprovado na Conferência Nacional de Educação, no Projeto de Lei no 8.035/2010 e na Lei $n^{0} 13.005 / 2014$. A comparação entre os temas relacionados à gestão democrática tratados na Conferência e os apresentados na lei aprovada revelam os limites desta em relação às expectativas e temáticas da Conferência. Ao mesmo tempo, as estratégias aprovadas nos planos estaduais de educação e relacionadas à gestão democrática 
revelam a importância dessa Conferência como forma de subsidiar o debate e a elaboração dos planos estaduais de educação.

\section{A CONFERÊNCIA NACIONAL DE EDUCAÇÃO DE 2010}

O documento final da Conae foi construído com base em seis eixos temáticos. O tema da gestão democrática é parte do eixo "qualidade da educação, gestão democrática e avaliação". Além desse, há os eixos relativos a organização e regulação da educação, permanência e sucesso escolar, valorização e formação profissional, financiamento e controle, e educação e trabalho.

Tal documento é o resultado das contribuições das conferências preparatórias estaduais e municipais, votadas e aprovadas na Conferência Nacional, a partir do texto base utilizado para o debate. As proposições apresentadas se aplicam às instituições de ensino, públicas e privadas, de nível básico e superior, bem como aos sistemas de ensino. O eixo trata inicialmente da gestão democrática, enfatizando a importância da autonomia das instituições educativas, principalmente universitárias, reforçando a relevância da existência de espaços colegiados de deliberação coletiva.

Nesse documento, a deliberação coletiva e a gestão democrática são entendidas como fatores de melhoria da qualidade da educação (Brasil. MEC, 2014). Entre as propostas aprovadas no documento final da Conferência, destacam-se:

Democratizar a gestão da educação e das instituições educativas (públicas e privadas), garantindo a participação de estudantes, profissionais da educação, pais/mães e/ou responsáveis e comunidade local na definição e realização das políticas educacionais, de modo a estabelecer o pleno funcionamento dos conselhos e órgãos colegiados de deliberação coletiva da área educacional, por meio da ampliação da participação da sociedade civil; instituir mecanismos democráticos - inclusive eleição direta de diretores/as e reitores/as, por exemplo -, para todas as instituições educativas (públicas e privadas) e para os sistemas de ensino; e, ainda, implantar formas colegiadas de gestão da escola, mediante lei específica. Lei própria deve garantir a eleição direta para diretores/as (gestores/ as) das escolas federais, estaduais, distritais e municipais da educação básica [...] garantir espaços articulados de decisão e deliberação coletivas para a educação nacional: Fórum Nacional de Educação, fóruns estaduais, municipais e Distrital de educação, Conferência Nacional de Educação, Conselho Nacional de Educação (CNE), conselhos estaduais (CEE) e municipais (CME); órgãos colegiados das instituições de educação superior e conselhos escolares. [...] A composição do Fórum Nacional de Educação deve refletir a composição da Comissão Organizadora Nacional da Conae, constituída pela ampla representação dos setores sociais envolvidos com a educação (sociedade civil organizada), com os correspondentes fóruns em âmbito dos estados, Distrito Federal e municípios, bem como fortalecer a autonomia e as atribuições dos conselhos Nacional, 
estaduais, do DF e municipais de educação, como órgãos de Estado. O Fórum Nacional de Educação deve ter pelo menos as seguintes incumbências: convocar e coordenar as próximas edições da Conae; acompanhar a tramitação do novo PNE (2011-2020) no Congresso Nacional; incidir pela implementação das diretrizes e deliberações tomadas nesta e nas demais edições da Conae [...] (Brasil. MEC, 2010, p. 43-44).

[...] Devem ser garantidas aos conselhos municipais de educação verbas específicas para sua gestão, bem com infraestrutura necessária para o seu funcionamento e garantia de liberação do/da conselheiro/a para participar efetivamente das reuniões, assegurada por meio de Lei. [...] definir, em lei nacional, diretrizes gerais e mecanismos institucionais, que regulamentem o artigo 206 da $\mathrm{CF} / 88$, concretizando o princípio de gestão democrática. (Brasil. MEC, 2010, p. 45).

Na análise da sequência das proposições sobre a gestão democrática é possível perceber que o texto as relaciona à qualidade da educação, afirmando que o tema envolve a compreensão de um conjunto de variáveis intraescolares e extraescolares, relacionando-as a diferentes espaços, atores e processos. Ainda segundo o texto, a qualidade deve ser entendida como um conceito histórico que se altera no tempo e espaço, revelando as dificuldades para a definição de um único e universal padrão de qualidade (Brasil. MEC, 2010).

O texto não apresenta proposições legislativas, mas expõe a reflexão sobre os princípios e diretrizes consideradas importantes para a efetivação das políticas de Estado relacionadas à educação e algumas das dimensões intraescolares e extraescolares que devem ser observadas para o estabelecimento de padrões de qualidade.

Ao lado dos processos de gestão democrática e dos parâmetros para a discussão sobre a qualidade de ensino, o documento conclui com proposições relacionadas à avaliação da educação, com foco nos sistemas educacionais e nas instituições de ensino.

Segundo o documento, a avaliação de sistemas educacionais é uma estratégia imprescindível para a geração de novas atitudes e práticas escolares, e deve considerar os diferentes atores e espaços, além de contemplar questões relacionadas ao desenvolvimento profissional e institucional e à infraestrutura (Brasil. MEC, 2010).

Nesse sentido, de acordo com o texto aprovado na Conae, a avaliação deve contribuir para formação e valorização profissional, possuir um caráter participativo, considerar questões relativas à infraestrutura das redes, à relação entre professores e estudantes, aos salários pagos aos profissionais, ao tempo do estudante na escola, entre outras características, e ser capaz de identificar questões relacionadas à gestão democrática (Brasil. MEC, 2010).

O texto ainda destaca a importância do projeto político-pedagógico da escola e do plano de desenvolvimento institucional das instituições de educação superior serem elaborados de maneira participativa, observando seu entrelaçamento com outros espaços e setores da sociedade e sua vinculação à realidade social das instituições. 
Dessa forma, no documento da Conae 2010, a gestão democrática está relacionada a melhoria da qualidade da educação. Nesse sentido, a definição dos padrões de qualidade acontece de forma participativa e dentro do contexto escolar, e a avaliação torna-se um instrumento de busca coletiva dessa qualidade, compondo, portanto, um tripé entre gestão democrática, qualidade e avaliação (Brasil. MEC, 2010).

Como já assinalado, o documento final foi encaminhado ao Poder Executivo que, por sua vez, o utilizou para elaborar e posteriormente encaminhar ao Congresso Nacional o Projeto de Lei $n^{\circ} 8.035 / 2010$, que se tornou o PNE.

\section{O PROJETO DE LEI N 8.035/2010 E A LEI N 13.005/2014}

O texto do PL n ${ }^{\circ}$ 8.035/2010, apresentado pelo Poder Executivo, possuía uma meta e duas estratégias. A meta era:

garantir, mediante lei específica aprovada no âmbito dos Estados, do Distrito Federal e dos Municípios, a nomeação comissionada de diretores de escola vinculada a critérios técnicos de mérito e desempenho e à participação da comunidade escolar. (Brasil, 2010).

A primeira estratégia era priorizar os repasses financeiros federais para os estados e municípios que aprovaram leis sobre a gestão democrática, considerando os critérios do Plano; a segunda estratégia era realizar uma prova nacional específica para os cargos de diretores escolares (Brasil, 2010).

O PL do Poder Executivo ratificou a autonomia política entre os entes nacionais, presente na LDB, ao estabelecer que estados e municípios deveriam aprovar leis disciplinando a gestão democrática em seus respectivos âmbitos de atuação. Talvez por isso o projeto de lei apenas tratou da nomeação de diretores, observando os critérios de mérito e desempenho e a participação da comunidade escolar, relacionando-as ao desembolso de recursos federais (Gomes, 2015).

Coube ao Congresso Nacional a adição de sete estratégias complementares ao projeto de lei original. O texto aprovado colocou como uma das diretrizes do Plano Nacional a promoção do princípio da gestão democrática da educação pública e definiu que as atribuições do Fórum Nacional da Educação consistem na realização do monitoramento contínuo e de avaliações periódicas da execução do PNE e do cumprimento de suas metas.

O projeto de lei ainda estabeleceu a obrigatoriedade da realização de outras duas conferências, realizadas em 2014 e 2018. Segundo a lei aprovada, o Fórum Nacional da Educação deve acompanhar a execução do PNE e o cumprimento de suas metas, promover a articulação das conferências nacionais de educação com as conferências regionais, estaduais e municipais que as precederem, enquanto as conferências 
seguintes têm "o objetivo de avaliar a execução deste PNE e subsidiar a elaboração do plano nacional de educação para o decênio subsequente” (Brasil, 2014, art. $6^{\circ}$, § $2^{\circ}$ ).

Outros dois pontos importantes tratados no corpo do projeto de lei se referiram à obrigatoriedade dos entes federativos aprovarem leis disciplinando a gestão democrática em suas jurisdições e elaborarem ou adequarem seus planos de educação à nova lei aprovada (Brasil, 2014).

No plano aprovado, a gestão democrática é uma das 20 metas e possui oito estratégias. O texto da Meta 19 do Plano define:

Assegurar condições, no prazo de 2 (dois) anos, para a efetivação da gestão democrática da educação, associada a critérios técnicos de mérito e desempenho e à consulta pública à comunidade escolar, no âmbito das escolas públicas, prevendo recursos e apoio técnico da União para tanto (Brasil, 2014).

A primeira estratégia da Meta se refere à transferência de recursos da União para os entes federados que atualizaram sua legislação sobre gestão democrática e que consideram, para a nomeação de diretores(as) de escola, a participação da comunidade e os critérios de mérito e desempenho. Essa primeira estratégia traz sentido ao texto geral da meta ao identificar o cargo de diretor de escola como objeto para a efetivação da gestão democrática e ao estabelecer a participação da comunidade escolar em sua escolha (Brasil, 2014).

A segunda estratégia do Plano Nacional trata de dois temas relacionados aos conselhos participativos no âmbito da educação. Nomeando expressamente os conselhos de acompanhamento e controle social (CACS), do Fundo de Manutenção e Desenvolvimento da Educação Básica e de Valorização dos Profissionais da Educação (Fundeb), os conselhos de alimentação escolar (CAE) e os conselhos regionais, a estratégia busca a ampliação da formação e do apoio a esses conselheiros, além de garantias de suas condições de funcionamento e trabalho (Brasil, 2014).

A terceira estratégia diz respeito à constituição de fóruns permanentes de educação, com atribuições semelhantes aos do Fórum Nacional, como coordenar as conferências locais e acompanhar a execução das metas nacionais e dos planos locais de educação (Brasil, 2014).

A quarta estratégia amplia a participação nos espaços colegiados no âmbito escolar, com os grêmios e a associação de pais buscando assegurar infraestrutura para o seu funcionamento. Ressalte-se que os estudantes do ensino básico têm assegurado a organização de grêmios desde 1985, através da Lei $\mathrm{n}^{0}$ 7.398, mas o Plano inovou ao atribuir ao grêmio e às Associações de Pais e Mestres (APMs) uma articulação orgânica com os conselhos escolares (Brasil, 2014).

A quinta estratégia também trata de conselhos participativos no âmbito dos sistemas e das escolas. Visa estimular a criação de conselhos municipais de educação 
e conselhos escolares, bem como a constituição de programas de formação de conselheiros, no mesmo sentido da segunda estratégia (Brasil, 2014).

A sexta estratégia repete a intenção do art. 14 da LDB ao propor a participação dos profissionais da educação, dos alunos e de seus familiares na elaboração do projeto político-pedagógico da escola, e acrescenta a participação da comunidade na elaboração dos currículos escolares, dos planos de gestão escolar e do regimento interno da escola. Por último, busca assegurar a participação dos pais na avaliação de docentes e gestores escolares (Brasil, 2014).

A sétima estratégia da Meta 19 visa garantir que as escolas tenham autonomia pedagógica, administrativa e de gestão financeira. A oitava e última estratégia trata também da formação, mas, dessa vez, dos diretores e gestores escolares, prevendo uma prova nacional para o cargo de diretor, na qual os estados e os municípios poderão usar os resultados por adesão (Brasil, 2014).

Comparado com o projeto de lei, observa-se que as estratégias aprovadas convergem em diversas proposições aprovadas no documento final da Conae, como o fortalecimento dos conselhos, a oferta de condições para seu funcionamento, o papel do Fórum Nacional de Educação, a ampliação da participação para outras esferas e grupos sociais, o apoio a mecanismos participativos dentro das escolas, a autonomia das escolas e a formação dos gestores escolares.

Com relação à nomeação de diretores, o texto da meta aprovada traz uma imprecisão, pois trata "da gestão democrática da educação, associada a critérios técnicos de mérito e desempenho e à consulta pública à comunidade escolar”, sem fazer qualquer referência ao cargo de diretor e ao mecanismo de participação.

Dessa forma, o tripé conceitual presente no documento final da Conae (qualidade, avaliação e gestão democrática) é desfeito na Meta 19, pois o texto da lei dissocia a gestão democrática do tema da qualidade ao criar a Meta 7, que estabelece "fomentar a qualidade da educação básica em todas as etapas e modalidades, com melhoria do fluxo escolar e da aprendizagem", sem referência direta à participação da comunidade (Brasil, 2014).

No âmbito da Meta 7, a participação da comunidade é abordada apenas quando trata do planejamento e da aplicação dos recursos, enquanto o documento final da Conae aborda a avaliação dos sistemas de maneira participativa, contextual e democrática.

\section{PLANOS ESTADUAIS DE EDUCAÇÃO}

A análise dos diversos planos estaduais aprovados demostrou que alguns se organizaram como espelhamentos da lei nacional, outros foram completamente alterados e adaptados à realidade local do estado. Nessa diversidade de situações, 
os temas contemplados e convergentes permitem avaliar a força das temáticas das conferências e da sociedade na elaboração de cada plano estadual de educação.

No PNE vigente, há uma determinação legal para que todos os entes federativos elaborem seus respectivos planos de educação e que isso ocorra de maneira participativa no prazo de um ano, contados a partir de junho de 2014, quando o PNE foi aprovado.

A LDB estabeleceu os papéis a serem desempenhados pela União, estados, municípios e escolas, também especificou os níveis e modalidades de ensino e regulou e regulamentou a estrutura e o funcionamento do ensino nacional. Dessa maneira, algumas metas presentes no PNE têm como principal agente responsável pela sua execução os estados e os municípios, ainda que em regime de colaboração entre entes federativos.

A eleição de diretores das escolas públicas, considerando critérios de mérito e desempenho, por exemplo, foi o tema principal dos debates legislativos relacionados à Meta 19 (Gomes, 2015) e se tornou o principal indicador para avaliar a efetividade dessa meta do Plano Nacional. Contudo, sua execução é de responsabilidade das redes estaduais e municipais de ensino.

Pelo fato dos estados e municípios serem os principais protagonistas na execução da gestão democrática da educação, suas estratégias para o alcance da meta possuem uma melhor aderência à realidade de cada uma das redes de ensino e, nesse sentido, são reveladoras dos desafios associados às especificidades educacionais de cada estado.

Os últimos dados disponíveis indicam que atualmente 19 unidades federativas selecionam seus diretores por meio de eleições e possuem a obrigatoriedade de participação em curso de formação em gestão escolar como pré-requisito para ocupar o cargo de diretor. Além desses, mais quatro estados selecionam seus diretores por meio de eleições, sem especificar a existência de critérios de mérito e desempenho utilizados na seleção. Dessa maneira, as eleições se tornaram o mecanismo mais consagrado pelos sistemas estaduais para consulta pública à comunidade escolar prevista no PNE (Brasil. Inep, 2018).

Considerando as determinações legais, há o seguinte cenário de planos estaduais de educação ${ }^{1}$ (Quadro 1), com as respectivas datas de aprovação: Maranhão, Mato Grosso do Sul e Mato Grosso aprovaram seus planos ainda em 2014, enquanto a maioria dos estados (18) aprovou seus planos no ano de 2015; os estados de Alagoas, Bahia, Ceará, Rio Grande do Norte e São Paulo tiveram seus planos aprovados em 2016, enquanto Minas Gerais aprovou seu plano em dezembro de 2018.

\footnotetext{
1 O estado do Rio de Janeiro aprovou, em 2009, seu plano estadual de educação previsto na Lei do PNE I, com prazo de 10 anos, de 2009 a 2018. Assim, em 2014, quando houve a aprovação do PNE II, o Plano Estadual de Educação (PEE) fluminense estava em vigência. No estado de Minas Gerais, em dezembro de 2018, foi aprovado na Assembleia Legislativa o PL n² 2.882/2015, transformado na Lei $\mathrm{n}^{\circ}$ 23.197/2018, que trata do PEE.
} 
QUADRO 1

LEIS DOS PLANOS ESTADUAIS DE EDUCAÇÃO DOS ESTADOS E DATA DE APROVAÇÃO - BRASIL

\begin{tabular}{|c|c|c|}
\hline Estado & Lei & Data \\
\hline Acre & Lei $\mathrm{n}^{0} 2.965$ & 2 de julho de 2015 \\
\hline Alagoas & Lei $\mathrm{n}^{0} 7.795$ & 22 de janeiro de 2016 \\
\hline Amapá & Lei $\mathrm{n}^{\circ} 1.907$ & 24 de junho de 2015 \\
\hline Amazonas & Lei $\mathrm{n}^{\circ} 4.183$ & 26 de junho de 2015 \\
\hline Bahia & Lei $n^{\circ} 13.559$ & 11 de maio de 2016 \\
\hline Ceará & Lei $n^{\circ} 16.025$ & 30 de maio de 2016 \\
\hline Distrito Federal & Lei $\mathrm{n}^{0} 5.499$ & 14 de julho 2015 \\
\hline Espírito Santo & Lei $n^{\circ} 10.182$ & 25 de junho de 2015 \\
\hline Goiás & Lei $\mathrm{n}^{\circ} 18.969$ & 22 de julho de 2015 \\
\hline Maranhão & Lei $\mathrm{n}^{\circ} 10.099$ & 11 de junho de 2014 \\
\hline Mato Grosso & Lei $\mathrm{n}^{\circ} 10.111$ & 6 de junho de 2014 \\
\hline Mato Grosso do Sul & Lei $\mathrm{n}^{0} 4.621$ & 22 de dezembro de 2014 \\
\hline Minas Gerais & Lei $n^{\circ} 23.197$ & 26 de dezembro de 2018 \\
\hline Pará & Lei $\mathrm{n}^{\circ} 8.186$ & 23 de junho de 2015 \\
\hline Paraíba & Lei $n^{\circ} 10.488$ & 23 de junho de 2015 \\
\hline Paraná & Lei $\mathrm{n}^{\circ} 18.492$ & 24 de junho de 2015 \\
\hline Pernambuco & Lei $\mathrm{n}^{\circ} 15.533$ & 23 de junho de 2015 \\
\hline Piauí & Lei $\mathrm{n}^{\circ} 6.733$ & 17 de dezembro de 2015 \\
\hline Rio de Janeiro & Lei $\mathrm{n}^{\circ} 5.597$ & 18 de dezembro de 2009 \\
\hline Rio Grande do Norte & Lei $n^{\circ} 10.049$ & 27 de janeiro de 2016 \\
\hline Rio Grande do Sul & Lei $n^{\circ} 14.705$ & 25 de junho de 2015 \\
\hline Rondônia & Lei $\mathrm{n}^{\circ} 3.565$ & 3 de junho de 2015 \\
\hline Roraima & Lei $\mathrm{n}^{\circ} 1.008$ & 3 de setembro de 2015 \\
\hline Santa Catarina & Lei $n^{\circ} 16.794$ & 14 de dezembro de 2015 \\
\hline São Paulo & Lei $\mathrm{n}^{\circ} 16.279$ & 8 de julho de 2016 \\
\hline Sergipe & Lei $\mathrm{n}^{\circ} 8.024$ & 4 de setembro de 2015 \\
\hline Tocantins & Lei $\mathrm{n}^{0} 2.097$ & 8 de julho de 2015 \\
\hline
\end{tabular}

Fonte: Elaboração própria.

Ressalta-se que em todos os planos estaduais há uma meta ou estratégia para a gestão democrática, mas entre estados que já possuíam lei anterior regulamentando 
a escolha de diretores, por exemplo, muitas vezes não existe referência à forma de seleção dos diretores no âmbito dos planos estaduais.

\section{AS ESTRATÉGIAS DOS PLANOS ESTADUAIS PARA A GESTÃO DEMOCRÁTICA}

A primeira leitura dos planos estaduais de educação sob a ótica da gestão democrática, objeto da Meta 19 do PNE, revela que tanto o texto legal quanto suas metas e estratégias em alguns casos possuem a mesma redação ou pequenas adaptações do Plano Nacional.

Nos 25 planos estaduais promulgados entre 2014 e 2016, existem 380 estratégias relacionadas à gestão democrática. Para a análise, foram construídas categorias com base em oito estratégias do Plano Nacional, o que permitiu identificar quais eram os temas presentes nas estratégias estaduais e os ausentes no Plano Nacional.

Além disso, estratégias com temas encontrados em apenas um plano estadual e sem correspondência em outros planos foram desconsideradas posteriormente. Como a intenção é avaliar como os planos contemplaram ou não as propostas do documento final da Conae, temas singulares de um único estado não interessaram à análise.

As estratégias estaduais foram classificadas com base em oito estratégias definidas na Meta 19 do Plano Nacional:

- Nomeação de diretores.

- Formação de conselheiros e fortalecimento dos conselhos.

- Fórum Permanente de Educação e acompanhamento da execução do PNE.

- Fortalecimento da participação através do grêmio e da APM.

- Fortalecimento dos conselhos escolares e municipais.

- Estímulos à participação da comunidade.

- Autonomia escolar.

- Formação e prova para diretores. (Brasil, 2014).

Como as estruturas de texto dos planos estaduais seguem, na maioria das vezes, o mesmo formato do Plano Nacional (20 metas), em muitos estados, a meta relacionada à gestão democrática recebeu, inclusive, a mesma numeração da meta do Plano Nacional (19), assim como repetiu suas estratégias.

Com base nessa classificação inicial, foram encontradas 98 estratégias estaduais não contidas nessas oito categorias. As estratégias estaduais que não se enquadraram nas oito categorias analíticas, oriundas do Plano Nacional e da Meta 19, foram analisadas e posteriormente classificadas da seguinte forma: 
- Educação nas prisões, no campo, nas áreas remanescentes de quilombos e indígenas (seis planos estaduais, sete estratégias).

- Transparência (cinco planos estaduais, sete estratégias).

- Gestão de pessoas (seis planos estaduais, seis estratégias).

- Avaliação (nove planos estaduais, onze estratégias).

Com base nessa segunda classificação, restaram ainda 67 estratégias não classificadas por estarem presentes em apenas um plano estadual. A seguir são apresentados os conteúdos das estratégias dos planos estaduais, segundo categorias elencadas.

\section{EDUCAÇÃO NAS PRISÕES, EM ESCOLAS QUILOMBOLAS, INDÍGENAS E DO CAMPO (6 ESTADOS)}

Destaca-se, nas estratégias relacionadas à gestão democrática, a atenção a grupos socialmente excluídos do direito à educação e de outros direitos sociais. As estratégias dos planos estaduais tratam da oferta de educação e da regularização do funcionamento das escolas indígenas, quilombolas, do campo e em prisões. Em comum, há o compromisso com uma educação especializada para esses grupos.

O tema da educação do campo, entre indígenas e quilombolas, aparece em outras metas do Plano Nacional e, especialmente, no art. $8^{\circ}$ da lei, que trata da adequação dos planos estaduais à nova lei aprovada, destacando estratégias que levem em consideração as especificidades dessas populações e assegurem "a equidade educacional e a diversidade cultural" (Brasil, 2014, art. $8^{\circ}, \S 1^{\circ}$, I). Nesse sentido, o tema foi reiterado em outras metas dos planos estaduais e do Plano Nacional.

Os planos dos estados de Tocantins (2015), Maranhão (2014), Rio Grande do Norte (2016), Santa Catarina (2015) e Espírito Santo (2015) elaboraram estratégias no âmbito da gestão democrática dirigidas especificamente às populações indígenas, quilombolas e do campo.

A regularização da organização e do funcionamento de escolas de educação básica destinadas a esses grupos é estratégia presente nos planos do Maranhão (2014) e do Rio Grande do Norte (2016). Outros planos, como o do estado do Tocantins (2015), propõem desenvolver políticas de apoio aos municípios para a oferta de educação no campo. No estado do Espírito Santo (2015) a estratégia visa promover uma gestão escolar que considere as especificidades desse público.

O plano estadual de Santa Catarina (2015), nesse sentido, possui uma estratégia mais abrangente ao propor a criação de uma comissão de educação indígena, garantindo a "participação dos povos indígenas no planejamento e acompanhamento da educação escolar indígena”. 
Tratando de outro grupo, no plano do estado do Pará (2015), entre as estratégias da gestão democrática, há incentivo à articulação com o plano estadual em educação nas prisões e do projeto político-pedagógico institucional dos jovens em medidas socioeducativas, trazendo estratégias específicas de formação educacional. Nesse sentido, a proposta está em consonância com as estratégias das Metas 7, 9 e 10 que estão relacionadas à educação de pessoas privadas de liberdade, tratando da oferta, inclusão e permanência desses jovens na escola em todos os estabelecimentos penais, assegurando formação específica para os(as) professores(as).

Ressalta-se que as populações dos grupos quilombolas, indígenas e do campo são citadas em outros momentos do Plano Nacional, em pelo menos 12 estratégias, e a educação nas prisões aparece em diversos pontos ao longo da lei. A associação entre gestão democrática e acesso e permanência, mais uma vez, se fez presente ao considerar as especificidades desses grupos e escolas.

\section{TRANSPARÊNCIA (5 ESTADOS)}

A transparência está associada ao fortalecimento da democracia na medida em que submete o Estado e seus agentes aos controles sociais, reduzindo as assimetrias entre cidadãos e agentes públicos, podendo servir como instrumento de gestão ao permitir maior controle sobre o setor público por parte da sociedade (Amaral, 2007). As estratégias estaduais relacionadas à gestão democrática tratam, em sua maioria, de criação de portais eletrônicos que informem sobre a aplicação dos recursos financeiros e humanos da educação.

O tema da transparência aparece no Plano Nacional ao tratar do financiamento da educação e propõe, na Estratégia 20.4, o fortalecimento dos mecanismos e instrumentos que assegurem a transparência e o controle social dos recursos públicos aplicados em educação.

A estratégia relativa ao financiamento da educação no Plano Nacional foi reproduzida nos planos estaduais de Santa Catarina (2015) e do Distrito Federal (2015) como estratégia da gestão democrática desses estados. Os planos estaduais de Roraima (2015) e Amapá (2015) associaram a gestão democrática à transparência dos recursos através da atualização do site da transparência dos recursos aplicados em educação, ao passo que o plano estadual do Piauí (2015) propôs a criação de um sistema de acompanhamento visando a transparência quanto ao recebimento e aos usos dos recursos aplicados na escola; o Paraná (2015) objetivou aprimorar o processo de planejamento de intervenção física nas escolas de forma transparente e democrática. Enquanto no Plano Nacional, as estratégias relacionadas à transparência no uso dos recursos públicos estão associadas à meta do financiamento, nos planos estaduais a questão é deslocada para o tema da gestão democrática. 


\section{GESTÃO DE PESSOAS (6 ESTADOS)}

A primeira estratégia da Meta 19 trata da nomeação de diretores de escolas públicas, por meio de consulta pública e considerando critérios de mérito e desempenho. Já nos planos estaduais a temática do mérito reaparece contemplando outros cargos relacionados à educação. Há também propostas de criação de novos cargos, relativas à jornada de trabalho e ao fluxo de pessoal.

Os planos estaduais dos estados do Ceará (2016), Rio Grande do Norte (2016) e Santa Catarina (2015) possuem em comum a proposta de definição de critérios técnicos para o provimento desses cargos, sendo que nos dois últimos planos definiu-se que esses cargos de gestão da educação sejam ocupados por profissionais da área. O plano do estado do Ceará (2016) aponta a seleção pública unificada para as equipes técnicas dos órgãos regionais de educação e estabelece a criação de critérios técnicos de mérito e desempenho para o acesso aos cargos.

No sentido da garantia da transparência na ocupação dos cargos de gestão educacional, o plano estadual do Amapá (2015) estabeleceu a criação de uma plataforma eletrônica para cadastro dos profissionais da secretaria de educação, com objetivo de permitir o acompanhamento do fluxo de pessoal nas atividades desempenhadas.

O plano estadual de Alagoas (2016) estabelece a jornada única dos profissionais da educação em apenas uma unidade escolar, como uma estratégia de valorização dos profissionais. O plano do estado do Amazonas (2016), que não realiza eleições para diretores de escolas públicas nem prevê a consulta pública em seu plano, propõe a criação do cargo de administrador escolar das escolas com funcionamento em três turnos.

\section{AVALIAÇÃO INSTITUCIONAL (9 ESTADOS)}

Na observação das estratégias dos planos estaduais, relacionadas à gestão democrática, que não foram contempladas entre as estratégias da Meta 19 do Plano Nacional de Educação, o primeiro tema que se destaca se refere à avaliação. O termo avaliação institucional é usado nos planos estaduais de Rondônia, Tocantins, Rio Grande do Norte, Paraná e Santa Catarina. Em outros quatro estados, os termos variam entre avaliação da gestão educacional, avaliação da gestão escolar democrática, autoavaliação e avaliação do núcleo gestor (Rondônia, 2015; Tocantins, 2015; Rio Grande do Norte, 2016; Paraná, 2015; Santa Catarina, 2015).

Detectou-se um debate sobre avaliação no qual, de um lado, há foco em resultados, com contrato de gestão e indicadores a serem alcançados e, do outro, uma preocupação em avaliar com base em mais informações contextuais, considerando a avaliação interna e externa das instituições e dos servidores. 
Essa controvérsia sobre avaliação ganha corpo na estratégia do plano estadual do Rio Grande do Sul. O plano gaúcho apresenta premissas importantes sobre avaliação. A estratégia gaúcha prevê "constituir sistemas de avaliação participativos... que incluam a avaliação interna e externa das instituições e dos servidores” (Rio Grande do Sul, 2015).

Em seguida, a estratégia delimita que devem ser:

mecanismos de avaliação que não incluam provas específicas aos servidores, [mas] a partir de uma produção coletiva de acordo com cada realidade interna e externa das instituições e dos servidores, e que nesse caso seja avaliado o desempenho e dedicação do próprio servidor e não os resultados obtidos junto aos alunos, com ênfase nos aspectos qualitativos sobre as quantitativos, considerando o contexto socioeconômico (...) garantida a participação das entidades representativas dos segmentos das comunidades escolares na definição do modelo de sistema e dos indicadores avaliativos, com a finalidade de diagnosticar a realidade, para embasar o planejamento e permitir a implementação de uma educação com qualidade social, respeitando as particularidades, incluindo direito de autodefesa aos servidores. (Rio Grande do Sul, 2015)

Em sentido oposto, no estado do Piauí, a estratégia consiste em:

realizar avaliação do núcleo gestor das escolas públicas (diretores, coordenadores e secretários), anualmente, através de comissão especializada da Seduc, com a finalidade de garantir a execução do contrato de gestão como instrumento de indicador de desempenho da gestão escolar. (Piauí, 2015).

Entre esses dois polos, o plano estadual de educação do Paraná (2015) tem como estratégia a criação de lei estadual para assegurar "permanente acompanhamento que consolide o processo de avaliação institucional das escolas da Educação Básica”. O plano do estado de Santa Catarina (2015) também possui como estratégia aprovar lei para a implantação da avaliação institucional "com a participação da comunidade escolar, incorporando seus resultados no Projeto Político Pedagógico e no Plano de Gestão”.

Os planos de educação dos estados do Rio Grande do Norte (2016) e de Rondônia (2015) apresentam entre suas estratégias para a gestão democrática a constituição da comissão de avaliação institucional, com participação de toda a comunidade. No caso do estado nordestino, a comissão tem como objetivo "elaborar as diretrizes voltadas para a avaliação institucional da gestão escolar” (Rio Grande do Norte, 2016).

Em Roraima, a estratégia é criar um sistema de avaliação "que envolva a participação dos pais de alunos na avaliação de docentes e gestores escolares" (Roraima, 2015), como previsto na estratégia da Meta 19 do PNE. No plano estadual de Alagoas (2016) se propõe "assegurar a construção coletiva por parte da comunidade escolar dos processos e instrumentos de avaliação da gestão educacional”. 
Em uma perspectiva mais próxima ao plano gaúcho e ao texto final da Conae, no plano do estado do Tocantins (2015), a proposta é estabelecer indicadores de avaliação institucional considerando o perfil dos alunos e dos profissionais, as condições de infraestrutura, os recursos pedagógicos e as características da gestão, "considerando o contexto cultural e econômico e, em outras dimensões relevantes”. A estratégia do plano do estado de Tocantins reproduz a Estratégia 7.3 do Plano Nacional, mantendo a relação entre qualidade, gestão democrática e avaliação ao reproduzi-la na meta da gestão democrática.

Importante frisar que o estado do Tocantins (2015) não realiza eleições como forma de escolha dos diretores de escolas da rede estadual, assim como o estado de Roraima (2015), embora o seu plano proponha a criação de um sistema de avaliação educacional que envolva a participação de pais e alunos na avaliação de docentes e gestores, conforme observado.

As estratégias do Rio Grande do Sul (2014) e do Piauí (2015) aparecem como dois polos, em que o primeiro não prevê mecanismos de responsabilização quando trata da avaliação, enquanto o segundo estabelece um contrato de gestão com indicadores de desempenho. Em meio a tudo isso, há estratégias nos planos estaduais de Rondônia (2015), Tocantins (2015), Rio Grande do Norte (2016), Paraná (2015) e Santa Catarina (2015) que propõem uma avaliação institucional e contextualizada.

\section{CONCLUSÕES}

A análise das estratégias contidas nos planos estaduais revelou temáticas comuns entre os estados e recuperou algumas das deliberações do documento final da Conferência Nacional de Educação (Conae), notadamente a avaliação da educação e a valorização do profissional da educação. Em alguns casos, houve o deslocamento de temas presentes em outras metas do Plano Nacional de Educação (PNE) para o âmbito da gestão democrática; em outros, houve o deslocamento inverso.

É importante ressaltar que as proposições contidas no documento final da Conae tratam de diversas temáticas, muitas delas impossíveis de serem abordadas em leis federais. O tema das eleições para diretores e reitores, de instituições públicas e privadas, é um exemplo da amplitude das propostas do documento da Conae e dos limites da lei do PNE nesse sentido.

Por outro lado, alguns temas que reaparecem nos planos estaduais, relacionados às estratégias de gestão democrática, o fazem justamente pelo fato dos estados possuírem sistemas próprios de ensino, nos quais se tornaram possíveis tais ações.

As estratégias relacionadas à transparência no uso dos recursos, assim como à preocupação com a educação nas prisões em áreas remanescentes de quilombos e indígenas, estão presentes na lei do PNE e no documento final da Conae, quando tratam 
da garantia do direito à educação de acordo com as necessidades de grupos culturais e sociais específicos. Todavia, alguns planos estaduais abordaram essas temáticas no âmbito da gestão democrática, o que revela uma de suas dimensões conceituais.

Um dos principais temas da gestão democrática no documento final da Conae, a qualidade de ensino tornou-se uma meta própria no PNE, mas desvinculada da gestão democrática. No texto da meta 7 do PNE, a qualidade da educação ficou circunscrita à aferição através dos indicadores do Sistema de Avaliação da Educação Básica (Saeb), enquanto a avaliação institucional e a autoavaliação das escolas aparecem como estratégias de meta, sem referência à gestão democrática ou a aspectos participativos da comunidade nesse processo de busca da qualidade.

Nesse caso, o tripé qualidade, avaliação e gestão democrática, dissociado no Plano Nacional, foi retomando em alguns planos estaduais, ainda que de maneira diversa no que se refere às propostas. A avaliação, além de ser o tema mais recorrente entre os planos estaduais analisados, e de possuir o maior número de estratégias, interfere diretamente nas condições de ensino, influenciando o conceito do que é educação pública e o que deve ser sua qualidade (Freitas, 2016). Segundo o autor, a avaliação, separada da participação, pode enfrentar dificuldades.

Nesse sentido, a avaliação institucional pode operar como mediação entre os resultados das avaliações em larga escala e os resultados obtidos em sala de aula, considerando os conhecimentos locais, o contexto no qual se insere a escola e a participação da comunidade na elaboração de propostas e definições sobre a qualidade da educação e sobre os projetos educacionais.

A presença da avaliação nos planos estaduais de educação sugere que, embora separada da gestão democrática no projeto de lei e na lei aprovada em 2014, alguns planos estaduais reafirmaram sua importância na perspectiva da gestão democrática, o que indica a relevância dos processos de discussão desenvolvidos nas conferências e retomados em planos estaduais.

\section{REFERÊNCIAS}

ACRE. Lei $n^{\circ}$ 2.965, de 2 de julho de 2015. Aprova o Plano Estadual de Educação para o decênio 2015-2024 e dá outras providências. Diário Oficial do Estado do Acre, Rio Branco, v. 38, n. 11589, 3 jul. 2015. p. 5-61.

ALAGOAS. Lei $\mathrm{n}^{0}$ 7.795, de 22 de janeiro de 2016. Aprova o Plano Estadual de Educação e dá outras providências. Diário Oficial do Estado de Alagoas, Maceió, 25 jan. 2016. 
AMAPÁ. Lei no 1.907, de 24 de junho de 2015. Dispõe sobre o Plano Estadual de Educação - PEE, para o decênio 2015-2025, e dá outras providências. Diário Oficial do Estado do Amapá, Macapá, n. 5982, 24 jun. 2015. p. 2.

AMARAL, M. S. Accountability, governo Local e democracia: investigação em portais municipais do estado da Bahia. Dissertação (Mestrado em Administração) - Escola de Administração, Universidade Federal da Bahia, Salvador, 2007.

AMAZONAS. Lei no 4.183 de 26 de junho de 2015Aprova o Plano Estadual de Educação do Amazonas e dá outras providências. Diário Oficial do Estado do Amazonas, Manaus, 26 jun. 2015. Disponível em: < https://sapl.al.am.leg.br/media/ sapl/public/normajuridica/2015/8637/8637_texto_integral.pdf $>$.

AVRITZER, L. Instituições participativas e desenho institucional: algumas considerações sobre a variação da participação no Brasil democrático. Opinião Pública, Campinas, v.14, n.1, p. 43-64, jun. 2008.

BAHIA. Lei n ${ }^{0}$ 13.559, de 11 de maio de 2016. Aprova o Plano Estadual de Educação da Bahia e dá outras providências. Diário Oficial do Estado da Bahia, Salvador, 12 maio 2016.

BRASIL. (Constituição 1988). Constituição da República Federativa do Brasil de 1988. Brasília, 1988.

BRASIL. (Constituição 1988). Emenda Constitucional no 59, de 11 de novembro de 2009. Acrescenta $\S 3^{\circ}$ ao art. 76 do Ato das Disposições Constitucionais Transitórias para reduzir, anualmente, a partir do exercício de 2009, o percentual da Desvinculação das Receitas da União incidente sobre os recursos destinados à manutenção e desenvolvimento do ensino de que trata o art. 212 da Constituição Federal, dá nova redação aos incisos I e VII do art. 208, de forma a prever a obrigatoriedade do ensino de quatro a dezessete anos e ampliar a abrangência dos programas suplementares para todas as etapas da educação básica, e dá nova redação ao $\S 4^{\circ}$ do art. 211 e ao $\S 3^{\circ}$ do art. 212 e ao caput do art. 214, com a inserção neste dispositivo de inciso VI. Diário Oficial da União, Brasília, DF, 12 nov. 2009. Seção 1, p. 8.

BRASIL. Lei $\mathrm{n}^{\circ}$ 9.394, de 20 de dezembro de 1996. Estabelece as diretrizes e bases da educação nacional. Diário Oficial da União, Brasília DF, 23 dez. 1996. Seção 1, p. 27833.

BRASIL. Lei no 10.172, de 9 de janeiro de 2001. Aprova o Plano Nacional de Educação e dá outras providências. Diário Oficial da União, Brasília DF, 10 de jan. 2001. Seção 1, p. 1. 
BRASIL. Lei $\mathrm{n}^{\mathrm{O}}$ 13.005, de 25 de junho de 2014. Aprova o Plano Nacional de Educação - PNE e dá outras providências. Diário Oficial da União, Brasília, DF, 26 jun. 2014. Seção 1, p. 1.

BRASIL. Instituto Nacional de Estudos e Pesquisas Educacionais Anísio Teixeira (Inep). Relatório do $2^{\circ}$ ciclo de monitoramento das metas do Plano Nacional de Educação. Brasília, 2018.

BRASIL. Ministério da Educação (MEC). Conae: construindo o sistema nacional articulado de educação: o Plano Nacional de Educação, diretrizes e estratégias: documento final. Brasília: MEC, 2010.

CALDEIRA, T.; Holston, J. Participatory urban planning in Brazil. Urban Studies, v. 52, n. 11, p. 2001-2017, 2015.

CEARÁ. Lei ${ }^{\circ}$ 16.025, de 30 de maio de 2016. Aprova o Plano Estadual de Educação (2016/2024). Diário Oficial do Estado do Ceará, Fortaleza, v. 8, n. 101, 1 jun. 2016. p. $1-19$.

CURY, C. R. J. Por um plano Nacional de Educação: nacional, federativo, democrático e efetivo. Revista Brasileira de Política e Administração da Educação. Porto Alegre, v. 25, n. 1, p. 13-30, jan./abr. 2009.

DISTRITO FEDERAL. Lei no 5.499, de 14 julho de 2015. Aprova o Plano Distrital de Educação - PDE e dá outras providências. Diário Oficial do Distrito Federal, Brasília, DF, n. 135, 15 jul. 2015

ESPÍRITO SANTO. Lei no 10.382, de 25 de junho de 2015. Aprova o Plano Estadual de Educação do Espírito Santo e dá outras providências. Diário Oficial do Estado do Espírito Santo, Vitória, n. 2429, 25 jun. 2015. p. 1-12.

FREITAS, L. C. Três teses sobre as reformas empresariais da educação: perdendo a ingenuidade. Cadernos Cedes, Campinas, v. 36, n. 99, p. 137-153, maio/ago. 2016.

GOIÁS. Lei no 18.969, de 22 de julho de 2015. Aprova o Plano Nacional de Educação para o decênio 2015.2025 e dá outras providências. Diário Oficial do Estado do Goiás, Goiânia, v. 178, n. 22129, 27 jul. 2015. p. 1-17.

GOMES, A. V. A. Gestão democrática no Plano Nacional de Educação 2014-2024. In: GOMES, A. V. A.; BRITTO, T. F. Plano Nacional de Educação: construção e perspectivas. Brasília: Câmara dos Deputados, Edições Câmara; Senado Federal, Edições Técnicas, 2015. p. 141-161. (Coleção Educadores). 
HOLSTON, J. A cidade modernista: uma crítica de Brasília e sua utopia.

Rio de Janeiro: Companhia das Letras, 1993.

MANIFESTO dos pioneiros da Educação Nova (1932) e dos educadores 1959. Recife: Fundação Joaquim Nabuco, Massangana, 2010. (Coleção Educadores).

MARANHÃO. Lei no 10.099, de 11 de junho 2014. Aprova o Plano Estadual de Educação do Estado do Maranhão e dá outras providências. Diário Oficial do Estado do Maranhão, São Luís, v. 108, n. 111, 11 jun. 2014. p. 29.

MATO GROSSO DO SUL. Lei $\mathrm{n}^{0}$ 4.621, 22 de dezembro de 2014. Aprova o Plano Estadual de Educação do Mato Grosso do Sul e dá outras providências. Diário Oficial do Estado do Mato Grosso do Sul, Campo Grande, n. 8828, 26 dez. 2014. p. 6.

MATO GROSSO. Lei ${ }^{0}$ 10.111, de 6 de junho de 2014. Dispõe sobre a revisão e alteração do Plano Estadual de Educação, instituído pela Lei no ${ }^{\circ}$ 8.806, de 10 de janeiro de 2008. Diário Oficial do Estado do Mato Grosso, Cuiabá, 6 jun. 2014.

MONLEVADE, J. A. C. Avaliação e Perspectiva do financiamento da educação pública no Brasil. CONFERENCIA NACIONAL DE EDUCAÇÃO CULTURA E DESPORTO, 1., 2001, Brasília. Anais... Brasília: Câmara dos Deputados, 2001. p. 43-48.

PARÁ. Lei no 8.186, de 23 de junho de 2015. Aprova o Plano Estadual de Educação PEE e dá outras providências. Diário Oficial do Estado do Pará, Belém, v. 125, n. 32913, 24 jun. 2015. p. 1-32.

PARAÍBA. Lei no 10.488, de 23 de junho de 2015. Aprova o Plano Estadual de Educação e dá outras providências. Diário Oficial do Estado da Paraíba, João Pessoa, 24 jun. 2015.

PARANÁ. Lei $\mathrm{n}^{0}$ 18.492, de 24 de junho de 2015. Plano Estadual de Educação e adoção de outras providências. Diário Oficial do Estado do Paraná, Curitiba, n. 9.479, 25 jun. 2015.

PERNAMBUCO. Lei n ${ }^{0}$ 15.533, de 23 de junho de 2015. Aprova o Plano Estadual de Educação. Diário Oficial do Estado de Pernambuco, Recife, 24 jun. 2015. p. 3.

Peroni, V. M. V.; Flores, M. L. R. Sistema nacional, plano educação no Brasil: articulações e tensões. Educação, Porto Alegre, v. 37, n. 2, p. 180-189, maio/ago. 2014. 
PIAUÍ. Lei no 6.733, de 17 de dezembro de 2015. Aprova o Plano Estadual de Educação - PEE e dá outras providências. Diário Oficial do Estado do Piauí, Teresina, v. 84, n. 239, 21 dez. 2015. p. 1-17.

REIS, T.; EGGERT, Edla. Ideologia de gênero: uma falácia construída sobre planos de educação brasileiros. Educação e Sociedade, Campinas, v. 38, nº . 138, p.9-26, jan./mar. 2017.

RIO DE JANEIRO. Lei $\mathrm{n}^{0}$ 5.597, de 18 de dezembro de 2009. Institui o Plano Estadual de Educação - PEE e dá outras providências. Diário Oficial do Estado do Rio de Janeiro, Rio de Janeiro, 21 dez. 2009.

RIO GRANDE DO NORTE. Lei $\mathrm{n}^{0} 10.049$, de 27 de janeiro de 2016. Aprova o Plano Estadual de Educação do Rio Grande do Norte (2015-2025) e dá outras providências. Diário Oficial do Estado do Rio Grande do Norte, Natal, 28 jan. 2016.

RIO GRANDE DO SUL. Lei ${ }^{\circ}$ 14.705, de 25 de junho de 2015. Institui o Plano estadual de Educação - PEE -, em cumprimento ao Plano Nacional de Educação PNE -, aprovado pela lei federal n ${ }^{0} 13.005$, de 24 de junho de 2014. Diário Oficial do Estado do Rio Grande do Sul, Porto Alegre, n. 120, 26 jun. 2015.

RONDÔNIA. Lei no 3.565, de 3 de junho de 2015. Institui o Plano Estadual de Educação de Rondônia. Diário Oficial do Estado de Rondônia, Porto Velho, n. 3565, 3 jun. 2015.

RORAIMA. Lei $\mathrm{n}^{\mathrm{O}}$ 1.008, de 3 setembro de 2015. Aprova o Plano Estadual de Educação 2014/2024 (PEE) e dá outras providências. Diário Oficial do Estado de Roraima, Boa Vista, v. 27, n. 3596, 3 set. 2015. p. 6-26.

SANTA CATARINA. Lei $\mathrm{n}^{0}$ 16.794, de 14 de dezembro de 2015. Aprova o Plano Estadual de Educação para o decênio e dá outras providências. Diário Oficial do Estado de Santa Catarina, Florianópolis, v. 81, n. 20205, 15 dez. 2015. p. 1-10.

SÃO PALO. Lei no 16.279 , de 8 de julho de 2016. Aprova o Plano Estadual de Educação de São Paulo e dá outras providências. Diário Oficial do Estado de São Paulo, São Paulo, 9 jul. 2016. p. 1.

SCOTT, J. C. Seeing like a state: how certain schemes to improve the human condition have failed. London: Yale University Press, 1998.

SERGIPE. Lei $\mathrm{n}^{0}$ 8.025, de 4 de setembro de 2015. Dispõe sobre o Plano Estadual de Educação e dá outras providências. Diário Oficial do Estado de Sergipe, Aracaju, n. 27291, 8 set. 2015. p. 1-9. 
SGUISSARDI, Valdemar. Prefácio. In: BRANDÃO, C. F. PNE passo a passo (Lei $n^{o}$ 10.172/2001): discussão dos objetivos e metas do Plano Nacional de Educação. São Paulo: Avercamp, 2006. p. 13-16.

SOUZA, D. B. Avaliações finais sobre o PNE 2001-2010 e preliminares do PNE 20142024. Estudos em Avaliação Educacional, São Paulo, v. 25, n. 59, p. 140-170, set./dez. 2014.

TOCANTINS. Lei n ${ }^{\circ}$ 2.977, de 8 de julho de 2015. Aprova o Plano Estadual de Educação do Tocantins - PEE/TO (2015-2025), e adota outras providências. Diário Oficial do Estado do Tocantins, Palmas, v. 27, n. 4411, 9 jul. 2015. p. 2-22. 
